\title{
ICC Nurturing Strategies in the Context of Sino- foreign Institutes
}

\author{
Xiaomei Zhu \\ Sino-German Institute of Design and Communication, Wanli University, Ningbo, China \\ Anwei Feng \\ Faculty of Humanities and Social Sciences, University of Nottingham, Ningbo, China
}

\begin{abstract}
This paper discusses intercultural communicative competence (ICC) education in the context of Sino-Foreign Institutes (SFIs). Through an overview of the development of internationalization of higher education in China, the paper puts forward four strategies that are widely adopted to facilitate the development of students ICC. The four strategies are provision of ICC specific courses, integration of ICC in subject courses, integration of ICC with foreign language education, and intercultural activities and projects. Towards the end, the paper argues that more empirical research is needed to evaluate the effects of the strategies on students' ICC and challenges the SFIs face in the post-pandemic era.
\end{abstract}

Index Terms-intercultural communicative competence, ICC nurturing strategies, Sino-foreign Institutes

\section{INTRODUCTION}

In the process of internationalization, the importance of intercultural communicative competence (ICC) (Byram, 2021) has been widely recognized as an essential component of global talents who can 'build and nurture constructive intercultural relationships' (Jackson, 2019, p.4) in various international cooperative programs. Deardorff defines ICC as 'the ability to communicate effectively and appropriately in intercultural situations based on one's intercultural knowledge, skills, and attitudes' (Deardorff, 2004, p.194). ICC is also widely believed to be one of the key objectives of universities to prepare their students for interactions with people from diverse linguistic and cultural backgrounds in this globalized world.

The pandemic of Covid 19 has a huge impact on globalization, and the rise in populism (Jackson, 2019) in some countries where political activities or ideas that claim to promote the interests and opinions of domestic ordinary people has further threatened cooperation among peoples and nations. Therefore, it can be predicted that the post-pandemic era will be complex and volatile in terms of cross-national communication. Thus, constructive and effective intercultural communication (IC) has never become more crucial. The Chinese government has realized it, in fact eight ministries including Ministry of Education (MOE) released guidelines in June 2020 to strengthen and accelerate internationalization of education in this new era (MOE, 2020).

Internationalization of higher education in China has developed prosperously, nevertheless. The number of students choosing to study aboard in China consistently increased six years in a row by 2020 (XingDongFang, 2020), though due to the impact of Covid 19, some students choose to cancel or postpone their plan in 2020 (iiMedia Research, 2020). It is commonly believed, however, that this is contemporary and the trend will continue. To achieve the aim of cultivating students who can 'act interculturally' (Feng, 2009), these Sino-Foreign Institutes (SFIs) should integrate intercultural education into their curriculum. However, what are the strategies of ICC education that may facilitate the cultivation of students ICC and what may impede it? This paper addresses this question with an overview of the previous studies on ICC education both in China and abroad.

\section{THE CONTEXT OF SiNO-FOREIGN INSTITUTES}

The process of internationalization of Chinese higher education has lasted for more than four decades starting from the late 1970s and it has not always been a smooth one. This paper will first go over this development briefly with focusing on some crucial milestones.

\section{A. Internationalization of Higher Education in China}

The primary form of transnational higher education (TNHE) in China has started its course after the economic reform and open-door policy in 1978 (Ong \& Chan, 2015). The development of TNHE in China, known as the 'ChineseForeign Cooperation in Running Schools' (CFCRS), has accelerated in the 1990s to support its soaring economic growth. In 2001, China became a member state in the World Trade Organization (WTO), which further boosted the development of CFCRS (ibid.).

Regulations of the People's Republic of China on Chinese-Foreign Cooperation in Running Schools issued in 2003 
by the State Council has provided legal protection for the stakeholders and led to the dramatic development of CFCRS (Wang, 2005, p.188). Up to 2017, HEIs in China had signed mutual recognition of academic qualifications and degrees with their counterparts in 46 countries and regions (Ma, 2021). By Jan. 2020, there were 66 CFCRS undergraduate institutions and 50 postgraduate institutions, 930 undergraduate programs and 220 postgraduate programs being listed officially by the Ministry of Education. These institutions and programs spread to 31 provinces and areas throughout mainland China. ${ }^{1}$

The implementing of The Outline of National Medium and Long-Term Education Reform and Development Plan (2010-2020) has no doubt further pushed this development. The objective of the outline is to establish 'a number of role model Sino-foreign institutions and projects' in the era of globalization of HE (MOE, 2010). Nevertheless, the development of transnational higher education in China at that time are seen as 'dramatic and chaotic' (Ong and Chan, 2015 , p.117). In six rounds of evaluation of CFCRS before 2009, there had been 22 programs which were rated as unqualified thus being shut down. Another 109 have since applied for voluntary withdrawal due to poor management (Sun \& Chen, 2018). The closure rate of CFCRS is generally felt depressing (Table I), 18\% on average, and with the closure rate of postgraduate programs reaching staggering $40 \%$.

TABLE I.

THE TOTAL Number OF CFCRS AND CLOSURE BeFORE JAN. 2020

\begin{tabular}{|l|l|l|l|l|}
\hline $\begin{array}{l}\text { Types } \\
\text { CFCRS/number }\end{array}$ & $\begin{array}{l}\text { Undergraduate } \\
\text { institutions }\end{array}$ & $\begin{array}{l}\text { Undergraduate } \\
\text { programs }\end{array}$ & $\begin{array}{l}\text { Postgraduate } \\
\text { institutions }\end{array}$ & $\begin{array}{l}\text { Postgraduate } \\
\text { programs }\end{array}$ \\
\hline Total number & 66 & 930 & 50 & 220 \\
\hline Closed & 5 & 197 & 2 & 87 \\
\hline The rate of closure & $7.5 \%$ & $21 \%$ & $4 \%$ & $39.5 \%$ \\
\hline
\end{tabular}

Source: Information Platform for the Supervisory Works on CFCRS. Retrieved and revised on Jan.30 2020 from

http://www.crs.jsj.edu.cn/aproval/orglists/1 \& http://www.crs.jsj.edu.cn/aproval/orglists/2

In this context, it is uncertain whether some newly established SFIs can provide their students with education which is seen as of good quality and effective in achieving objectives of internationalization. One of the key objectives, many educators and researchers argue, is to equip the students with intercultural communicative competence so that they may survive and thrive in intercultural encounters. Students who lack intercultural awareness will experience serious cultural shocks and painful transition from the home country to the host country. Therefore, ICC training needs to be permeated into the whole curriculum of CFCRS and be evaluated to ensure its effectiveness at the same time. That is exactly what most scholars believe to be the strongest rationales for international learning experience (Deardorff, 2004; Byram, 2018).

Nevertheless, most of the existing research has been focusing on Chinese students' cultural and academic experiences abroad (Tian, 2008; Wang, 2010). There is limited attention paid to home students in SFIs and to the strategies the SFIs adopt to provide ICC education for this group of students.

\section{B. The Role of English in SFIs}

In this globalized world, English is widely used in business, science, and government. In fact, it is the world language in practice, that is English as the lingua franca (ELF). It means in today's international interactions, English is more frequently used by non-native speakers than by native speakers (Kaur, 2011). According to the United Nations statistics in 2015, non-native English speaker has reached about 1,500 million, which hasn't included the official use of English in international organizations or in numerous academic publications (Candel-Mora, 2015).

Apparently, the role English plays in communication between native and non-native speakers is different from that among non-native speakers where there is no presence of native speakers. Linguistic, cultural, and power issues could vary hugely in each situation. In SFIs where English is the first language of the foreign university, such as the University of Nottingham Ningbo China (UNNC) or Xi'an Jiaotong-Liverpool University (XJTLU), the native speakers of English enjoy a superiority covertly or overtly in interactions, particularly in formal domains. On the other hand, there are quite a number of SFIs where English is used for communication and teaching, but is the mother tongue of neither side (for example, the Sino-German Institute at Zhejiang Wanli University), the power issue may reflect itself in very different ways as there is no immediate advantage for either party. This phenomenon is well worth studying as the number of such SFIs in Shanghai alone is as high as 36, these SFIs in nationwide are also developing fast ${ }^{2}$.

Of course, linguistic skills alone do not guarantee satisfactory communication outcomes, because it is quite possible for someone who is fluent with several languages yet lacks familiarity with cultures other than one's own (Sewell, 2013). As a result, the interaction between language and culture in the context of ELF is dynamic, multifaceted, and sometimes even ambivalent. It is therefore the work of the educators, including language teachers and subject teachers from SFIs to provide students with critical cultural awareness of language variations (ibid.) and intercultural communication. In short, it is the combination or integration of the linguistic and intercultural skills that will prepare students to enter variety of discourse communities in intercultural encounters.

1 The data is retrieved from http://www.crs.jsj.edu.cn/aproval/orglists/2 on Jan. 30th, 2020.

2 The data is retrieved from http://www.crs.jsj.edu.cn/aproval/orglists/2 on June 20th 2021. 


\section{Strategies Adopted to Nurture Students' ICC}

A holistic review of the previous studies on ICC education in general and studies conducted in SFIs in particular, we could identify four key strategies that are used to facilitate the development of students ICC. They are ICC specific courses, integration of ICC in subject courses, integration of ICC with foreign language education, and intercultural activities and projects.

\section{A. ICC-specific Course Offered in SFIs}

In China, the study of intercultural communication as a subject started in the early 1980s, with approximately 300 papers being published in the following twenty years ( $\mathrm{Li}, 2002)$. Since the culture turn of the new millennia, great progress has been made both in ICC research and in practice of intercultural education. This focus on ICC has become a necessity with the development of internationalization of high education and has been well supported by the government (MOE, 2010, 2017). Studies on ICC courses have also become prosperous.

From one of the biggest platforms of Chinese journals, Weipu, 228 journal articles could be found through a search under the key word of 'ICC courses', with 28 of them being grouped as from first class journals. ${ }^{1}$ Various innovative ideas and attempts in ICC pedagogy are identifiable. For example, by encouraging students to interview foreigners and display the outcome in class, Zhang Li (2013) helped her students to perceive cultural differences through personal experience, enhancing their cultural sensitivity, tolerance, and flexibility, and building up their ICC.

Some have integrated new technology into ICC course to make it more effective. Liang (2010) applied networking in intercultural communication courses by encouraging her students to correspond with students from cooperative U.S. universities. From the data of questionnaires and interviews, Liang found that students' intercultural communication ability has been improved in cognition, affection and behavior. There are also those who have explored incorporating flipped classroom and MOOC (Massive Open Online Courses) in intercultural courses (Chi et al., 2016; Wang, 2018) and reported positive outcomes.

While most studies of ICC courses highlight the aspects of teaching methods and modes, informed by constructivist theory, Chen and Wang (2013) proposed the ICC course mode of 'learning - communication experience - ICC'. Based on this model, they designed an Intercultural Communication Course whose teaching procedures take into account both language skills and communication ability in order to reach the goal of cultivating college students' cross-cultural communication ability. They reported that this new teaching mode is more effective in improving students' autonomic learning, linguistic skills, cooperation with group members, intercultural communication and learning strategies.

While educators and researchers have developed some strategies and models for ICC nurturing, some have conducted evaluation of the existing practice. In the context of SFIs, 59 papers were retrieved under the keywords of ICC courses and CFCRS, among which less than ten articles are relevant to the context of SFIs. After interviewing Chinese students and French teachers in a Sino-French Institution, for example, Jin and Guo (2018) found that Chinese students studying in France generally lack cross-cultural communication skills, are poor in linguistic skills and poor in practicing and innovation. Besides, they cannot fit in the group activities of projects completion and formative evaluation system. These may at least partly explain the expelling of 8,000 Chinese students by US universities in 2015 (Wholeren, 2015 ).

In their paper, Jin and Guo (2018) not only analyzed the reasons of the hardship students face but also put forward seven suggestions, among which three are about intercultural communicative competence. They concluded that the SFI is responsible for their students' poor academic and intercultural performance and should do more to equip their students with skills they need to study in France. Kuang's (2014) research based on the questionnaire of the students who will go to study in Germany draws similar conclusion of deficiency of ICC in curriculum design.

This accumulating research has presented a panorama of intercultural study in China which demonstrates huge progress being made for last two decades in developing strategies and practical model for ICC education. Nevertheless, the problems found by the studies cannot be ignored. Though, there are some studies attempted to deal with them from different aspects (Chen and Wang, 2013; Jin and Guo, 2018), for such a complex issue in a wide variety of context, the effects are far from satisfactory. The innovative strategies, variety of models adopted so far and evaluative studies, however, are assets for designing, implementing and assessing future ICC training courses for specific contexts.

\section{B. Integration of ICC in Subject Courses}

Though ICC specific courses are vital in cultivating students' ICC systematically, it is usually found to be insufficient alone. Intercultural teaching integrated into subject courses has the advantage of addressing cultural diversity specifically in relation to everyday teaching practice of various subjects (Dunn et. Al., 2009, p.534) and thus it has become a strategy in many contexts. These subjects give intercultural learning detailed contexts within different borders and make significant contributions to the cultivating of students' ICC.

To address the potential epistemological conflicts between intercultural learning which focuses on diversity and highly structured subject knowledge, Nordgren (2017) adopts the concept of 'powerful knowledge' (Young, 2008) to justify incorporating intercultural learning into school subjects. Young defines powerful knowledge as specialized knowledge that every student should have a right to learn to better understand and explain the world (ibid.). Therefore,

1. The data is retrieved from http://qikan.cqvip.com on Feb. 4th, 2020, surveying papers from 2009-2018. 
disciplinary knowledge is an important resource to achieve the goal of egalitarian education rather than an end for its own sake. This gives epistemic legitimacy to integrating intercultural teaching with school subjects, as this powerful knowledge may include knowledge that is intercultural. To some extent, the intercultural goals of education are largely based on the expected outcome of subject specialization in the process of internationalization of education.

There are many studies on intercultural disciplinary teaching at tertiary level. In 'Intercultural Competence in Higher Education: International Approaches, Assessment and Application', Deardorff and Arasaratnam-Smith (2017) have included ten papers of case studies on different subject courses focusing on developing students' intercultural competence. The case studies involve a wide range of different subjects, such as medicine, art and business; and took place in countries in America, Europe and Asia. The issues studied range from motivation of integrating intercultural teaching into subject courses; institutional context; disciplinary context; teaching methodology; students' attitude to measuring outcomes.

Krebs (2020) has reviewed these case studies and other attempts of improving students' ICC in different courses. He summarizes that though these studies have provided a diverse possibility of practices, they have not reached any agreement on 'pedagogical actions' (Krebs, 2020:38). After synthesizing the commonalities across the efforts and presenting their creativity in practice, he stresses the value of outcome assessment and gives proposals for further research. These proposals include extending intercultural teaching to alumni in professional context, designing effective intercultural subject courses throughout the degree programs and studying on beneficial classroom interventions.

It is not rare to the integration of ICC into subject courses in SFIs in recent years in China (Xia \& Ren, 2019). The SFI where the first author works requires that all its three majors (brand design, brand communication and brand management) and their subject courses to permeate intercultural communication education whenever applicable. After two years of curriculum construction, the SFI has developed several courses which have successfully integrated ICC into subject teaching and two of courses have won the title of Provincial Excellent Courses.

\section{Integration of ICC with Foreign Language Education}

It is widely believed that intercultural communication is an indispensable part of foreign language education (Feng, 2007; Liddicoat \& Scarino, 2013; Byram, 2021). Byram (2018, 2021), in particular, has persistently advocated integrating foreign language education (FLE) with the development of students' ICC. He believes foreign language teaching has a responsibility to prepare learners for interaction with people from other cultural backgrounds, teaching them intercultural skills, attitudes, and knowledge (Byram, 2018, p.140).

However, this cultural FLE is not always well accepted in China and there are heated debates on English education at all levels, especially at tertiary education in teaching College English (English education for non-English major students). It lies in Chinese government's principle of zhongxue wei ti xixue wei yong, which refers to adopting valuefree western science and technology for pragmatic purpose of developing Chinese economy while keep intact the essence of traditional Chinese culture (Gil \& Adamson, 2011). Thus, English could be nothing more than a tool to achieve this goal. However, as a component of culture and medium of communication, language is also dynamic, complex, and powerful. The integration of ICC into FLE has drawn more serious debates among academics and educators.

The core of the debate seems to lie in what should be the fundamental objectives of English teaching and in turn its course system, namely, English for General Purpose (EGP) or English for Specific Purposes (ESP). As a strong advocate of ESP, Cai (2017) claims that the most important goal of English teaching in university should be training students who are both professionally competent and are fluent in English communication. He represents those who believe "the most significant function of a language is a tool of communication" (P. 3). Valuing only the instrumental role of English, these educators reject involving cultural education in English teaching (Cai, 2018).

Other commentators such as S.R. Wang (2011), on the other hand, believe ESP, together with EGP and English for General Education (EGE), is an integrated part of College English teaching (p. 3). He disagrees with Cai to that ESP is the only way to the future development of College English teaching in all colleges and universities (Cai, 2018). S.R. Wang (2011) states that College English teaching should help students understand foreign civilization (including ways of thinking and living habits), look at foreign culture and core values with a critical eye, be familiar with Chinese and foreign cultural differences, and cultivate intercultural communication skills.

Integrating culture with FLE gradually is gaining momentum among policy makers and EFL stakeholders (Zhang, 2012; Yang, 2014; Wang, 2016; Sun, 2016) despite constant debates. It is officially established when Requirements on College English Teaching (2007) define the nature of college English as "both instrumental and humanistic" (p. 3). And Guidelines on College English Teaching (2017) explicitly includes intercultural communication as a major branch of College English, enjoying the same status as ESP and EGP (MOE, 2017).

Despite the growing recognition of ICC in English teaching in theory and policy making, there are still many problems. The most prominent two, according to Zhang (2012), are firstly; cultural teaching in practice is an accessory to language teaching thus it is not systematic. Secondly, the unclear objectives and incomplete teaching content has long been a troubling issue. During the years, many scholars and practitioners have contributed to address the problems. For example, Zhang and Yao (2020) have proposed a theoretical framework in the Chinese context: 'Integrated Model for Chinese Students' Intercultural Competence Development' (Fig.1). 


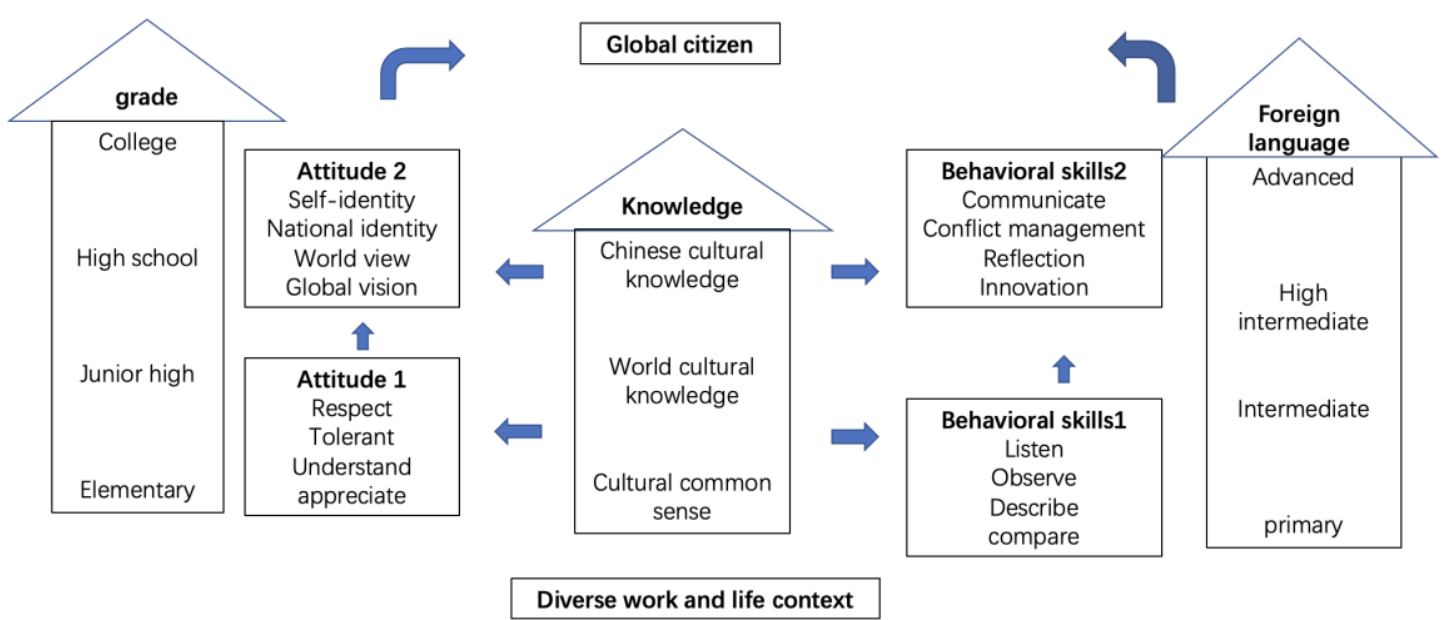

Figure 1. Integrated Model for Chinese Students' Intercultural Competence Development

This model states clearly that the objective of FLE is to educate students to be global citizens and achieving this need to integrate ICC components like attitudes, knowledges, and skills into FLE from primary school to university. Their study is not only theoretical but also practical. It ranges from designing intercultural textbooks for English class at different levels to organizing regional and national intercultural competence contests (Zhang et al., 2018).

\section{Intercultural Activities and Projects}

To improve students' ICC, it is essential for them to learn or experience more critical incidents (Flanagan, 1954). Critical incident refers to a communication situation which makes a participant(s) in an intercultural encounter feel so uncomfortable, amused, confused, or even shocked that this incident stays in mind. These incidents, like stories, involve characters, a cultural setting, a plot line, and an ending (De Frankrijker, 1998). The endings of the critical incidents usually relate to some cultural misunderstanding, awkwardness or difficulty, which are thought provoking.

Therefore, educators of foreign language courses and intercultural communicative courses often design class activities that involve critical incidents. These activities may include case analysis, role play, shooting video, interviewing, taking pictures, group discussion, experience sharing, storytelling, reflective journal writing, etc. Teachers may also encourage students to empathize with the characters of the critical incident by asking how they would do if they were the characters as such events which usually involve cultural clashes where something unexpected may happen. The objective of the critical incidents in intercultural communication is to avoid misunderstandings, accomplish tasks and develop relationships.

When designing intercultural activities, teachers should also consider the students' cultural background and ICC level, so that the activities generally match the students' level of intercultural competence. Therefore, it is necessary for teacher to conduct a survey to have a general idea about students ICC. Otherwise, too challenging tasks may trigger the defensive responses of the learners which is detrimental to the effect of learning (Fig. 2).

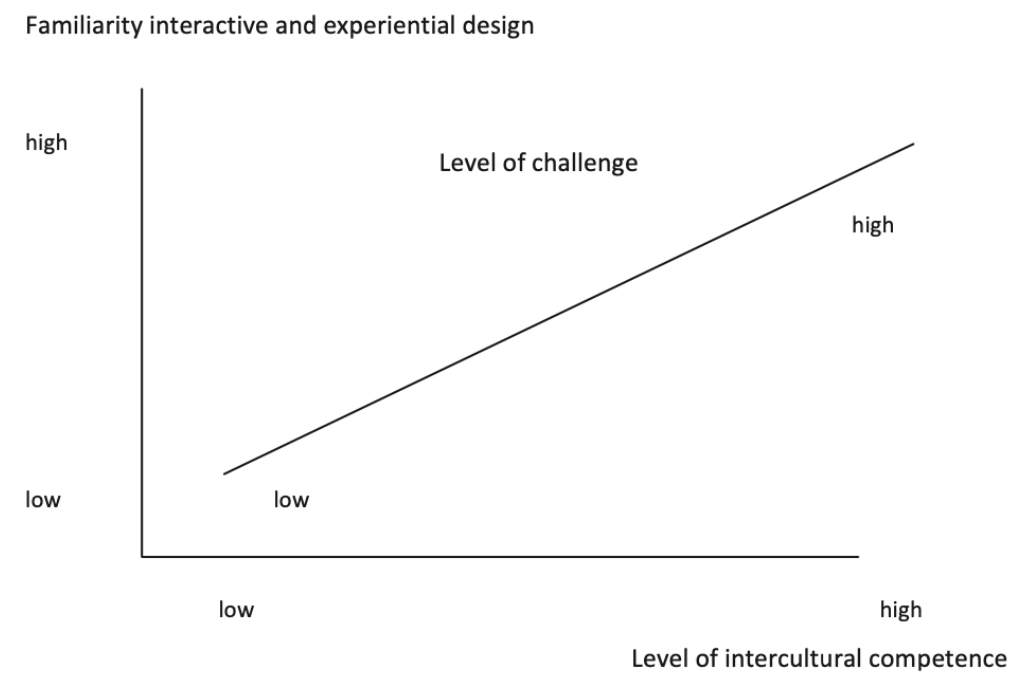

Figure 2 Level of Challenge in Program Design (Gregersen-Hermans \& Pusch, 2012)

This program design figure shows how individuals will be more likely to be successful in the tasks they are confident 
of. Therefore, designing activities at the appropriate level of challenge will be more likely to ensure emotional responses, active participation, and transformative learning experience (Gregersen-Hermans \& Pusch, 2012, p.29).

Universities may also initiate projects that provide genuine intercultural encounters at the institutional level. These projects may involve organizing international fair participating by both domestic and overseas students, short term exchange or internship programs to cooperative universities abroad. In this way, students may have more opportunities to either witness or experience critical incidents from which they may see the difference among cultures and be aware of the potential misunderstandings (ibid.).

In Qin and Dai (2013)'s research, they have evaluated intercultural communication courses offered by an SFI. These IC courses all involve activities like case study, group presentation and report writing. They have found from data that these activities are more helpful than the traditional lecturing class in developing students' multicultural awareness.

To achieve optimal learning outcome, it is vital to help student to form the habit of reflection after critical incidents through, for example, reflective journals (Holly, 1989). The first author has been adopting reflective writing in her intercultural communication course in her SFI. By keeping a reflective journal, student can have the chance to relive the incident, have a dialogue with facts and interpretations, and learn from experience. It has been one of the most popular activities from students' feedback. If student have formed the habit of keeping ICC reflective journals, it can be very beneficial to the students' lifelong learning of ICC.

\section{CONCLUSION}

Universities especially SFIs must respond to the wider global societal needs that arise from increasing intercultural interactions in the background of globalization. This means transforming students into graduates who are capable of 'behaving and communicating effectively and appropriately in intercultural situations' (Deardorff \& Bok, 2009), which is also the goal of modern universities. While there are scores of studies on theoretical study of ICC (Deardorff, 2006; Kupka, 2008; Feng, 2009; Spencer-Oatey and Franklin, 2009; Byram, 2021) and some on application and assessment (Deardorff \& Bok, 2009; Deardorff \& Arasaratnasm-Smith, 2017), there is still a rarity of empirical studies in the context of Sino-foreign institutions, particularly the studies to analyse the effectiveness of the strategies adopted to develop the ICC curriculum.

This overview of strategies is of value to shed some lights on the field of intercultural communicative competence curriculum design at tertiary level in the context of SFI and ELF, especially in the context of rapid development of internationalization of $\mathrm{HE}$ where many may compromise on quality. Further studies may focus on the evaluation of the four strategies, namely, ICC specific courses, integration of ICC in subject courses, integration of ICC with foreign language education, and intercultural activities and projects, and the interrelationship between them, in nurturing what are normally called global citizens or international talents (a term often used in China) the world desires for the $21^{\text {st }}$ century.

\section{ACKNOWLEDGMENTS}

The authors wish to thank UNNC and ZWU. This work was supported in part by a grant from the project 'A Study on Integrating Intercultural Education in Language teaching in SFIs' and the project number is Y202044909.

\section{REFERENCES}

[1] Byram, M. (2018). An essay on internationalism in foreign language education. Intercultural communication education. 1 (2), 64-82.

[2] Byram, M. (2021). Teaching and assessing intercultural communicative competence. Clevedon: Multilingual Matters.

[3] Cai, J.G. (2017). Review of Chinese Tertiary English Education: Failure and Lessons. Journal of Northeast Normal University: Philosophy and Social Sciences, 5, 1-7.

[4] Cai, J.G. (2018). ESP in China Revisited: Beliefs and Concepts: Reflection of FLT since China's Reform and Opening up in 1978. Foreign Languages Research, 35(02), 42-47.

[5] Chen, W. and Wang, X. L. (2013). Construction of English intercultural communication teaching model from the perspective of constructivism - a case study of English intercultural communication course construction in Nanjing University of posts and telecommunications. Journal of Southwest Agricultural University: Social Science Edition, 6, 152-156.

[6] Chi, R. B., Zhang, H. L., \& Gu, L. X. (2016). Transforming Traditional Courses into MOOCs: A Case Analysis of the Intercultural Communication Courses. Media in Foreign Language Instruction, 6, 29-34.

[7] De Frankrijker, H. 1998. Cross-cultural learning from incidents, the critical incident method: some applications concerning the practice of teacher education and parent support. European Journal of Intercultural Studies, 9, 55-70.

[8] Deardorff, D. K. (2004). The identification and assessment of intercultural competence as a student outcome of international education at institutions of higher education in the United States. North Carolina State University, Raleigh (Unpublished dissertation).

[9] Deardorff, D. K. (2006). Identification and Assessment of Intercultural Competence as a Student Outcome of Internationalization. Journal of Studies in International Education, 10(3), 241-266. doi:10.1177/1028315306287002.

[10] Deardorff, D., \& Bok, D. (2009). The Sage handbook of intercultural competence. Thousand Oaks, Calif. London: Sage Publications.

[11] Deardorff, D. \& Arasaratam-Smith, L. (2017). Intercultural competence in higher education: International approaches, 
assessment and application. UK: Routledge.

[12] Dunn, W., Kirova, A., Cooley, M. \& Ogilvie, G. (2009). Fostering Intercultural Inquiry in Subject-Area Curriculum Courses. Canadian Journal of Education, 32(3), 533-557.

[13] Feng, A. W. (2007). Intercultural space for bilingual education. In A. W. Feng (Ed.), Bilingual education in China (pp. 259286). Clevedon, UK: Multilingual Matters.

[14] Feng, A. W. (2009). Identity, "acting interculturally" and aims for bilingual education: an example from China. Journal of Multilingual and Multicultural Development, 30(4), 283-296

[15] Feng, A. W. (Ed.). (2011). Introduction: the Apex of 'the Third Wave'---English language across Great China. In A.W. Feng (eds.), English language education across Greater China (pp. 1-20). Bristol, UK: Multilingual Matters.

[16] Flanagan, J.C. (1954). The critical incident technique. Psychological Bulletin, 51 (4), 327-358.

[17] Gil, J., \& Adamson, B. (2011). The English language in China: A sociolinguistic profile. In A. Feng (Eds.), English language education across Greater China (pp. 23-45). Bristol, UK: Multilingual Matters.

[18] Gregersen-Hermans, J. \& Pusch, M. (2012). How to design and assess an intercultural learning experience. In GregersenHermans, J., Pusch, M. \& Deardorff, D. (Eds.). Building cultural competence: Innovative activities and models (pp.23-41). Sterling, Va.: Stylus Pub.

[19] Holly, M. (1989). Writing to grow: Keeping a personal-professional journal. Portsmouth, N.H.: Heinemann.

[20] Hu, W. Z. (2013). How to position intercultural communicative competence in foreign language teaching. Foreign Language World, 6, 2-8

[21] iiMedia Research. (2020). A summary of the current situation and trend of China's overseas study in 2020. https://zhuanlan.zhihu.com/p/224953615 (accessed 20/8/2020).

[22] Jackson, J. (2019). Introducing Language and Intercultural Communication. (2nd ed.). Routledge.

[23] Jin S. S. and Guo F. Y. (2018). A study on the cross-cultural competence and adaptability of Chinese students studying abroad - a case study of the postgraduate engineering students from Sino-French cooperative college in France. Modern University Education, 3, 94-102.

[24] Krebs, Katharine C. (2020). Global, international, and intercultural learning in university classrooms across the disciplines. Research in Comparative and International Education, 15(1), 36-51. https://doi.org/10.1177/1745499920901947.

[25] Kuang. J. (2014). Research on Cultivating Mode of Intercultural Competence of Overseas Students in Germany: Taking German National Condition Lesson as an Example. Journal of Shi Jiazhuang railway university: social science edition, 4, 7073.

[26] Kupka, B. (2008). Creation of an instrument to assess intercultural communication competence for strategic international human resource management. Doctoral dissertation, University of Otago, Otago, New Zealand.

[27] Liang, L. J. (2010). Application of Network Communication Method In Intercultural Communication Courses. China Educational Technology, 12, 45-49.

[28] Liddicoat, A. \& Scarino, A. (2013). Intercultural Language Teaching and Learning. UK: Wiley-Blackwell.

[29] Ministry of Education (MOE). (2010). Outline of National Medium- and Long-Term Education Reform and Development Plan (2010-2020). http://www.moe.gov.cn/srcsite/A01/s7048/201007/t20100729_171904.html (accessed 10/8/2019).

[30] Ministry of Education. (MOE) (2017). Guidelines on College English Teaching.

[31] Ministry of Education. (MOE) (2020). Accelerating and Expanding the opening up of education in the new era. http://www.moe.gov.cn/jyb_xwfb/s5147/202006/t20200623_467784.html (accessed 10/8/2020).

[32] Nordgren, K. (2017) Powerful knowledge, intercultural learning and history education, Journal of Curriculum Studies, 49 (5), 663-682, DOI: 10.1080/00220272.2017.1320430.

[33] Qin, L.L. \& Dai, W.D. (2013) A Study on Intercultural Communication Courses Oriented to Develop Multicultural Awareness. Technology Enhanced Foreign Languages, 154, 56-65.

[34] Spencer-Oatey, H., \& Franklin, P. (2009). Intercultural Interaction: A Multidisciplinary Approach to Intercultural Communication. Research and Practice in Applied Linguistics. London: Palgrave Macmillan Limited.

[35] Sun, Y. Z. (2016). Foreign Language Education and intercultural Competence Training. Foreign Languages in China, 3, 17-22

[36] Wang, S. (2018). An Exploration of Active Learning Strategies in Flipped Classroom_ Based on the Course of Chinese Culture \& Intercultural Communication for International Students. Media in Foreign Language Instruction, 4, 23-29.

[37] Wang, S.R. (2011) Some Thoughts on College English Teaching in China. Foreign Language Teaching Theory and Practice, $01,1-5$.

[38] Wang, S.R. (2016) Interpretation of 'the Guidelines on College English Teaching'. Foreign language world, 03, 2-10.

[39] Wang, X. Y. \& Pan, Y. L. (2019). Status and Enlightenment of Cross-cultural Foreign Language Teaching Research in China: Based on Bibliometric Analysis (2000-2018). Foreign Language World, 4, 76-84

[40] Wholeren. (2015). White Paper on Dismissal Issues of Chinese Students in the United States 2015. https://www.wholeren.com/wp-content/uploads/2015/06/2015-WhitePaper_CN.pdf (accessed 11/6/2018).

[41] Xia, X. G.\& Ren, X.(2019). Forty Years of Reform and Opening Up: Exploration and Practice of Cross-cultural Mathematics Education in Guizhou. The Future Educator, (7), 29-32.

[42] XingDongFang. (2020) Report on Chinese Students' Overseas Study. http://edu.people.com.cn/n1/2020/0630/c100631765168.html (accessed 22/7/2020).

[43] Yang, L.Y. (2014). The Significance of the "Outreaching Strategy" in the New Period. People's Forum, 23, 186-188.

[44] Young, M. (2008). Bringing knowledge back in: From social constructivism to social realism in the sociology of education. Abingdon: Routledge.

[45] Zhang, H. L. (2012). Foreign language teaching guided by intercultural education: Past, present and future. Foreign Language World, 02, 2-7.

[46] Zhang, L. (2013). Practice-based Teaching in Cross-cultural Communication: Interview Presentation Review. Journal of Shanxi Finance and Economics University, S3, 79-85

[47] Zhang, H. L., Yu, Y. D. \& Shen, X. T. (2018). Research on intercultural Competence Assessment based on competition. 
Foreign Language World, 01, 52-61.

[48] Zhang, H.L., \& Yao, C.Y. (2020). Integrated Model for Chinese Students' Intercultural Competence Development. Foreign Language World, 04, 35-44.

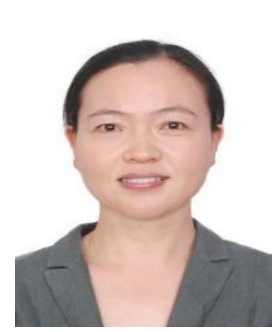

Xiaomei Zhu was born in Jiangsu Province, China in February 1977. She is pursuing a Professional Doctorate Degree of Education in University of Nottingham, Ningbo, China. She holds a M.A. in English literature from Shanghai International Studies University, Shanghai, China.

At present, she is a lecturer teaching College English in Sino-German Institute of Design and Communication, Wanli University, Zhejiang, China. Her published articles include: [1] Xiaomei Zhu (2004). A Study on Teaching Reading in College --- Two Ways of Improving Reading. Journal of Wanli Universit.17, 164-166 [2] Xiaomei Zhu (2015). The Feature and Strategy of Journalistic Translation. Journal of Test Weekly. G4, 29-31 [3] Xiaomei Zhu (2017). The Study of Teaching College English Reading Based on the Teaching Platform of Moodle. Journal of Qiannan Normal University for Nationalities. 37.3, 64-68. Her research interests are intercultural language teaching and pedagogy.

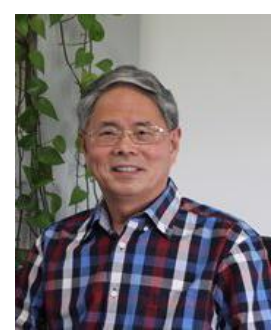

Anwei Feng. Professor in Language Education, School of Education and English, Faculty of Humanities and Social Sciences.

Anwei Feng is professor in language education. He joined The University of Nottingham Ningbo China (UNNC) in September 2013. Professor Feng holds an MA degree in applied linguistics and a PhD in language education. He has had teaching and research experience in tertiary institutions in many countries/regions such as China, Qatar, Hong Kong, Singapore, and the UK. Before he joined UNNC, Professor Feng was Director of the Graduate School in College of Education and Lifelong Learning (CELL) of Bangor University, UK. He is guest professor at a number of universities in China, including Guangdong Foreign Studies University, SIAS International University, Yunnan Normal University, Qujing Normal University, Southwest Forestry University, and Qinghai University for Nationalities.

Professor Anwei Feng teaches, supervises and researches in bilingualism and bilingual education, intercultural studies in education, TESOL, international and comparative education, and minority language education. He supervises $\mathrm{PhD}$ and Education Doctorate students whose thesis topics range from 'trilingualism and trilingual education', 'transnational education (TNE)', 'bilingual education for pre-school children', 'intercultural team teaching', 'ethnographic studies of third-culture kids in international schools', 'intercultural education in multicultural societies', 'lexical approach to teaching Chinese as a second/foreign language', to 'mass media, intercultural competence and TESOL', for different contexts. Professor Feng welcomes queries and applications for doctorate studies related to these areas. 